\title{
Renal Cell Carcinoma with
}

\section{Unusual Metastasis to the Small}

Intestine Manifesting as Extensive Polyposis: Successful Management with Intraoperative Therapeutic Endoscopy

\author{
Pankaj G. Vashi Elham Abboud Digant Gupta \\ Cancer Treatment Centers of America ${ }^{\circledR}$ at Midwestern Regional Medical Center, \\ Zion, III., USA
}

\section{Key Words}

Renal cell carcinoma - Metastasis - Gastrointestinal bleeding · Small intestine . Therapeutic endoscopy

\begin{abstract}
We present here a rare clinical case of a 53-year-old gentleman with metastasis from renal cell carcinoma (RCC) to the small intestine presenting with extensive polyposis and massive gastrointestinal bleeding which was successfully managed with intraoperative endoscopic polypectomy and segmental small bowel resection. The patient presented with melena 2 weeks after right nephrectomy for RCC. Capsule endoscopy found extensive polyposis throughout the small bowel, and the histological features confirmed the diagnosis of metastatic RCC. The patient eventually underwent laparotomy with intraoperative endoscopy of the entire small bowel. Most of the polyps were removed by snare polypectomy. Three segments of the small bowel with extensive transmural involvement had to be resected with primary anastomosis. In the 2 months following his surgery, the patient had no further evidence of gastrointestinal bleeding. The decision of meticulously removing close to 100 polyps by intraoperative endoscopy prevented the patient from requiring total small bowel resection and lifelong dependence on parenteral nutrition. In conclusion, gastrointestinal bleeding in a patient with known RCC should always trigger full gastrointestinal work-up including capsule endoscopy and, if necessary, double balloon enteroscopy.
\end{abstract}




\section{Introduction}

Renal cell carcinoma (RCC) is the third most common genitourinary cancer site after prostate and bladder cancer [1] and comprises $2-3 \%$ of all cancers in the United States [2]. The incidence of RCC ranges from 5 to 10 cases/100,000 population, with the rate being 1.6 times higher in men than in women [2]. Incidence rates of RCC differ among various ethnic groups and are highest among African Americans and lowest among Asian Americans and Pacific Islanders, and these reflect the rates of their countries of origin. On the other hand, mortality rates are dramatically higher for Native Americans, with Asian Americans and Pacific Islanders experiencing the lowest rates [1]. The risk factors for RCC include cigarette smoking, obesity, hypertension, reproductive and hormonal factors such as parity, physical activity, dietary factors such as consumption of processed meat and alcohol, long-term dialysis and environmental and occupational factors such as exposure to asbestos, petroleum products and cadmium $[3,4]$.

RCC manifests in a number of ways with localized symptoms such as pain, hematuria or abdominal mass or systemic symptoms such as weight loss, anorexia and pyrexia or with a number of other paraneoplastic syndromes. The tumor is commonly large at presentation and symptoms may not occur until relatively late in the disease [5]. If detected early, RCC can be treated surgically, and 5-year survival rates approaching $85 \%$ can be achieved for patients with organ-confined disease (stages T1, T2, and N0). 40-50\% of RCC patients develop metastatic disease. $20-30 \%$ present with metastases and $20-30 \%$ relapse distantly after curative nephrectomy [6].

Only 7\% of RCCs metastasize to distant organs [7], the most frequent sites of metastasis being the lung, lymph nodes, liver, bone and adrenal glands [8]. However, many unusual sites of metastasis of RCC have been cited in the literature, namely stomach [9], gallbladder [10], oropharynx [11], left ventricle [12], skin [13, 14], tonsils [15], spleen [16], pancreas [17], pituitary gland [18], thyroid [19, 20], breast [21], testicles [22], gastrocnemius muscle [23], ciliary body [4] and small intestine [7, 8, 24, 25]. Commonly, cancers metastasizing to the small bowel arise from the lung, head and neck, breast, esophagus and malignant melanomas [7] and occurrences of metastatic deposits from RCC to the small intestine are exceedingly rare phenomena, with only $7.1 \%$ of all metastatic tumors to the small intestine being accounted for by RCC [8].

Here we present a rare clinical case of a 53-year-old gentleman with metastasis from RCC to the small intestine presenting with extensive polyposis and massive gastrointestinal bleeding which was successfully managed with intraoperative endoscopic polypectomy and segmental small bowel resection.

\section{Case Report}

The patient was a 53-year-old gentleman with a known history of coronary artery disease status post coronary stenting who started experiencing progressive shortness of breath and chest pain in early January 2011. He presented to the local emergency room with increasing chest pain and shortness of breath. He underwent a cardiac work-up, which was essentially unremarkable. However, at that point, he was found to be anemic with a hemoglobin $(\mathrm{Hg})$ of $7 \%$ and a hematocrit $(\mathrm{Hc})$ of $21 \%$. He was transfused packed cells which relieved his symptoms. A CT scan of the abdomen showed a large lesion in the right kidney consistent with primary RCC. He underwent upper endoscopy and colonoscopy, which were reported to be negative. The patient continued to have occult positive stool. He decided to get a second opinion at our institution. 
His initial evaluation at our institution revealed low but stable $\mathrm{Hg} / \mathrm{Hc}$. Three days later, the patient underwent elective right nephrectomy. The pathology revealed an $11 \times 9 \times 6 \mathrm{~cm}$ RCC (clear cell type) with renal vein and perinephric adipose metastasis. Postoperatively, the patient had an uneventful hospital stay with a transient drop in $\mathrm{Hg} / \mathrm{Hc}$ requiring 2 units of packed cell transfusion before discharge, a week after surgery.

Two weeks later, the patient again presented to his local emergency room with melena and severe symptomatic anemia requiring multiple transfusions. Once stable, he was transferred to our facility for further management. He received 4 more units of packed cells over the next 4 days. Upper endoscopy revealed 2 small vascular polyps in the proximal duodenum, biopsy of which confirmed metastasis from RCC (fig. 1). This was followed by mesenteric and celiac angiograms which did not show any evidence of tumor blush or active bleeding. One of the branches of the celiac artery thought to be supplying the proximal small bowel was embolized with coils. There was no further bleeding and the patient was discharged. A repeat CT scan showed a small collection of fluid at the previous surgical nephrectomy site with no other abnormality. The patient continued to have melenotic stools off and on with a slow drop in $\mathrm{Hg} / \mathrm{Hc}$. Three weeks later the patient was readmitted with repeated complaints of weakness and severe anemia requiring more transfusions. Repeat colonoscopy was found to be negative. He underwent small bowel enteroscopy which showed multiple vascular polyps throughout the upper small bowel. He underwent capsule endoscopy, which confirmed extensive polyposis throughout the small bowel (ig. 2), some of them being large with ulcerations. A surgical consultation initiated a tumor board discussion and a dilemma on appropriate surgical intervention. It was reasoned that resection of the entire small bowel would cause permanent short bowel syndrome with lifelong dependence on parenteral nutrition.

The patient eventually underwent laparotomy with intraoperative endoscopy of the entire small bowel achieved by making two small openings in the small bowel. With the help of the surgeon, most of the polyps were removed by snare polypectomy (fig. 3 ). Three segments of the small bowel (fig. 4) totaling only $60 \mathrm{~cm}$ with extensive transmural involvement had to be resected with primary anastomosis. After $4 \mathrm{~h}$ of intraoperative endoscopy, the entire small bowel was clear of any polyps. A total of 70 polyps were reviewed by the pathologist. All of them were metastasis from RCC. Almost equal numbers of polyps were not sent for pathology after polypectomy. Postoperatively, the patient did not require any more transfusions. He was eventually discharged on the 7 th postoperative day with normal bowel function and a low but stable $\mathrm{Hg} / \mathrm{Hc}$. Because of significant weight loss and poor appetite over the previous 3 months, the patient was sent home on parenteral nutrition. In the 2 months following his surgery, the patient had no further evidence of gastrointestinal bleeding. He was started on oral sorafenib and is being followed closely by his oncologist. While his prognosis is guarded, this patient has significant improvement in his quality of life with no need of frequent hospitalizations and transfusions.

\section{Discussion}

It is extremely rare for RCC to metastasize to the small bowel. Very few cases have been documented regarding metastasis of RCC to different regions of the small intestine, namely duodenum [24-26], jejunum [7, 8, 27-29], and ileum [30]. The common feature across all these case reports was the presence of a solitary metastatic lesion in the small intestine. These solitary lesions have been reported from after 6 months up to 13 years following initial nephrectomy [7, 8, 24-29]. Most of these lesions were treated with surgical resection followed by chemotherapy. We report here the first case of RCC metastasizing to the small intestine in the form of extensive polyposis presenting as gastrointestinal bleeding.

The possible etiology of extensive small bowel metastasis in the form of polyposis with sparing of the colon is puzzling. The likely possibility may be transient showering of multiple tumor emboli in the celiac and mesenteric arteries. The fact that our patient was 
already bleeding before his diagnosis suggests that these polyps had been present for a while. However, it still does not explain the sparing of the entire colon.

The decision of meticulously removing close to 100 polyps by intraoperative endoscopy prevented the patient from requiring total small bowel resection and lifelong dependence on parenteral nutrition. Such endoscopic intervention was only possible by applying a great team approach to a patient with previously unreported metastatic RCC to the small bowel.

In conclusion, gastrointestinal bleeding in a patient with known RCC should always trigger full gastrointestinal work-up including capsule endoscopy and, if necessary, double balloon enteroscopy. We present a treatment option of intraoperative therapeutic endoscopy that can be employed in any patient with extensive metastatic small bowel polyposis from any etiology. Hopefully this case report will stimulate physicians and oncologists to 'think outside the box' and continue to come up with innovative treatment ideas to help their patients.

\section{Acknowledgement}

This study was funded by Cancer Treatment Centers of America ${ }^{\circledR}$.

\section{Disclosure Statement}

All authors declare that there are no potential conflicts (financial, professional, or personal) relevant to this paper.

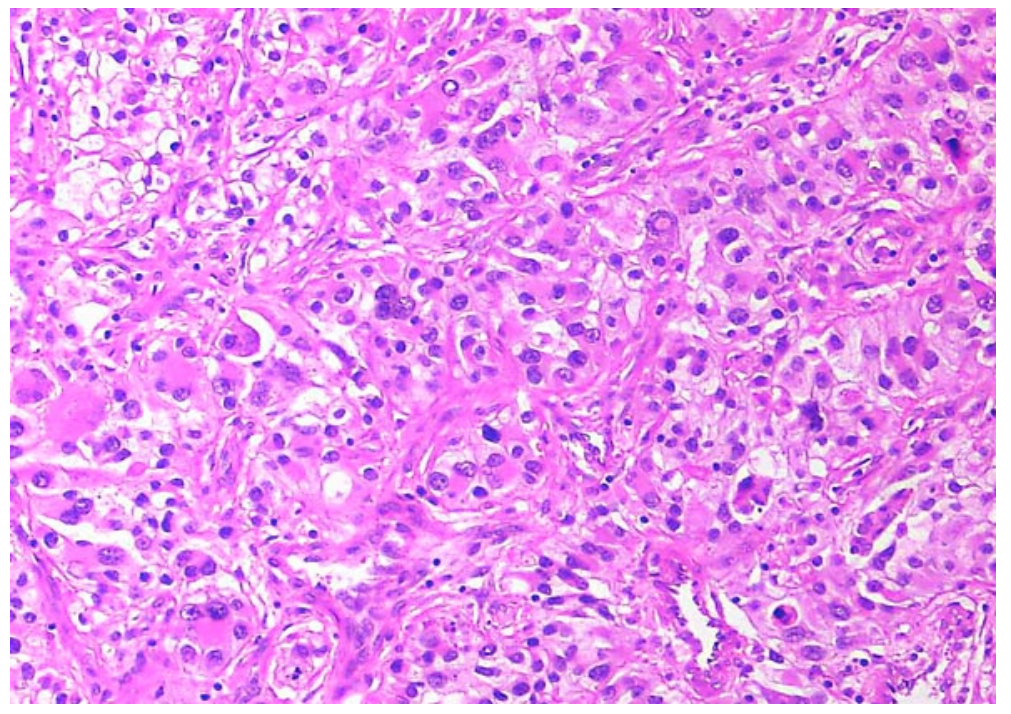

Fig. 1. Microscopic image $(10 \times)$ of a polyp showing nests of epithelial cells with marked nuclear pleomorphism, some with clear cytoplasm. Nuclei are large with prominent nucleoli. 

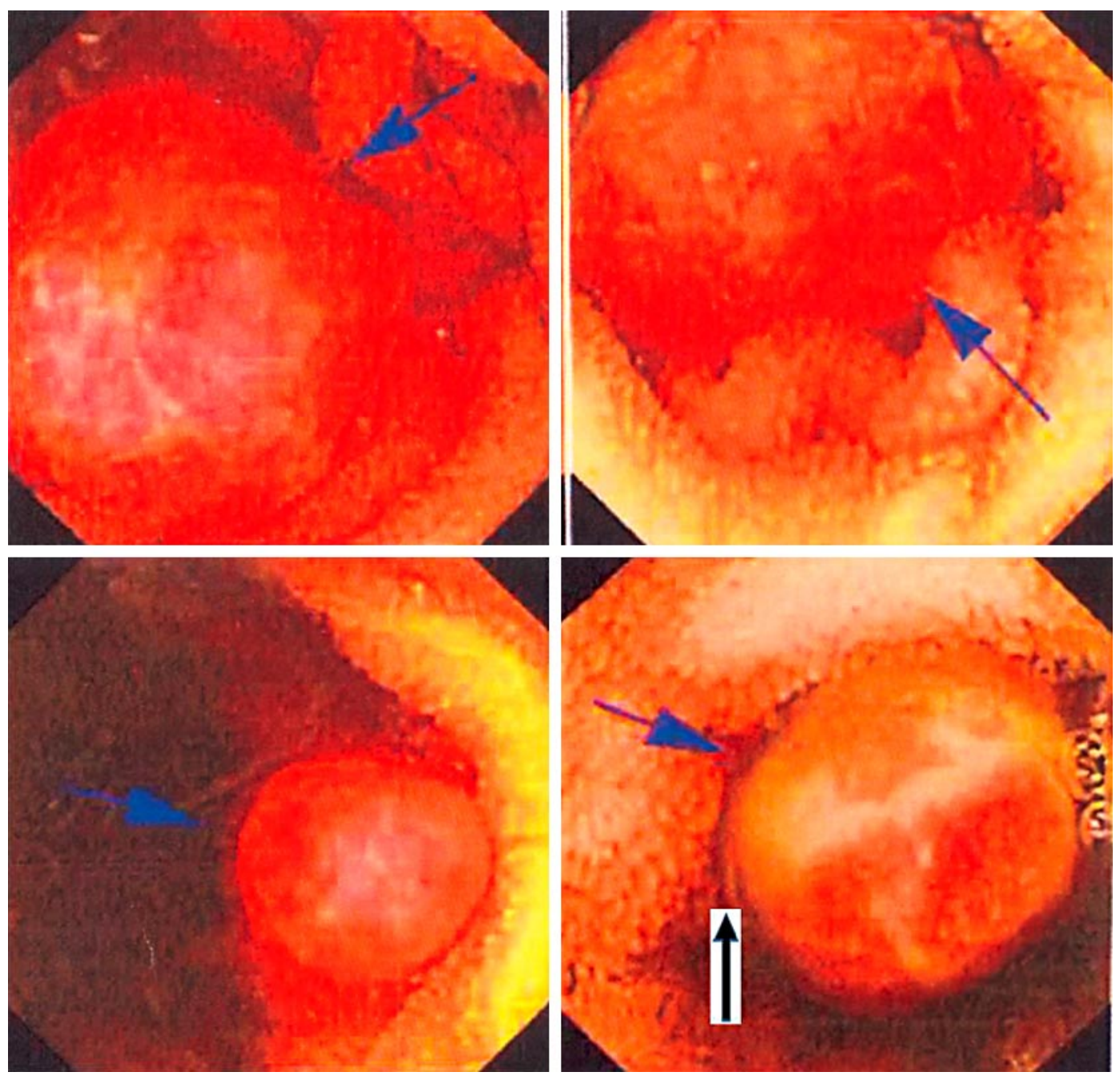

Fig. 2. Capsule endoscopy pictures showing multiple small bowel polyps throughout the jejunum and ileum. These polyps are of different sizes ranging from 0.5 to $2 \mathrm{~cm}$. One polyp is showing ulceration. 


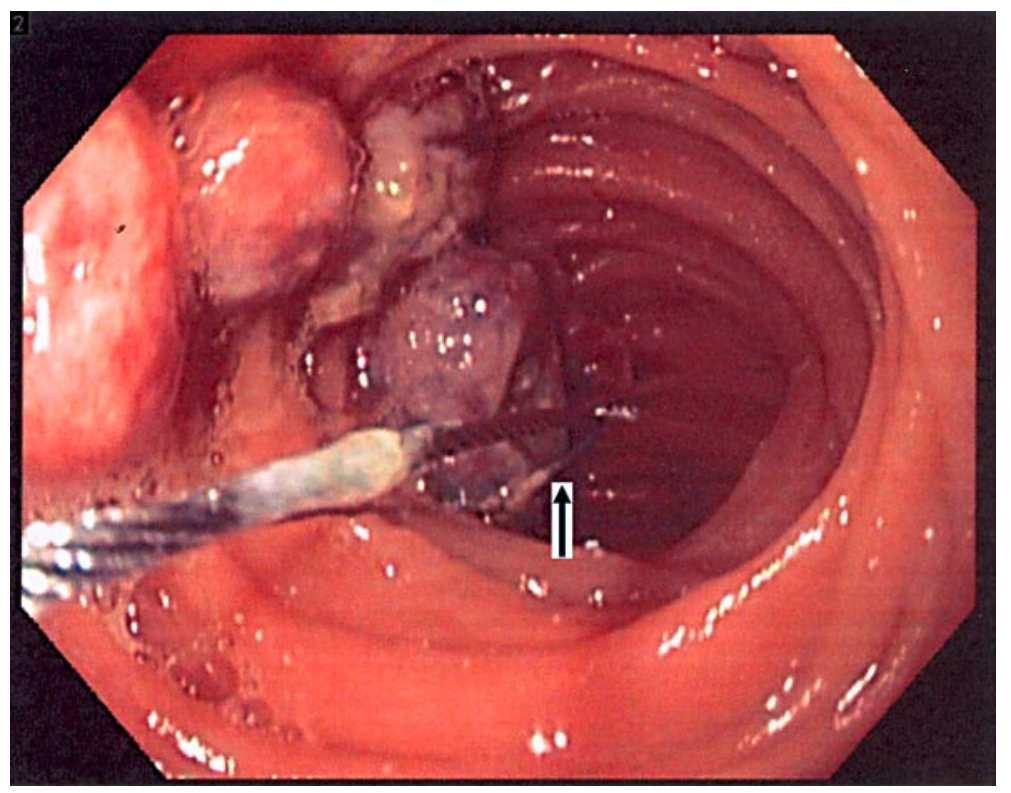

Fig. 3. Intraoperative small bowel endoscopy showing multiple polyps. The polyps are being snared with cautery snare polypectomy.

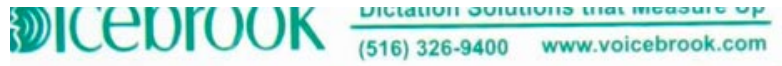

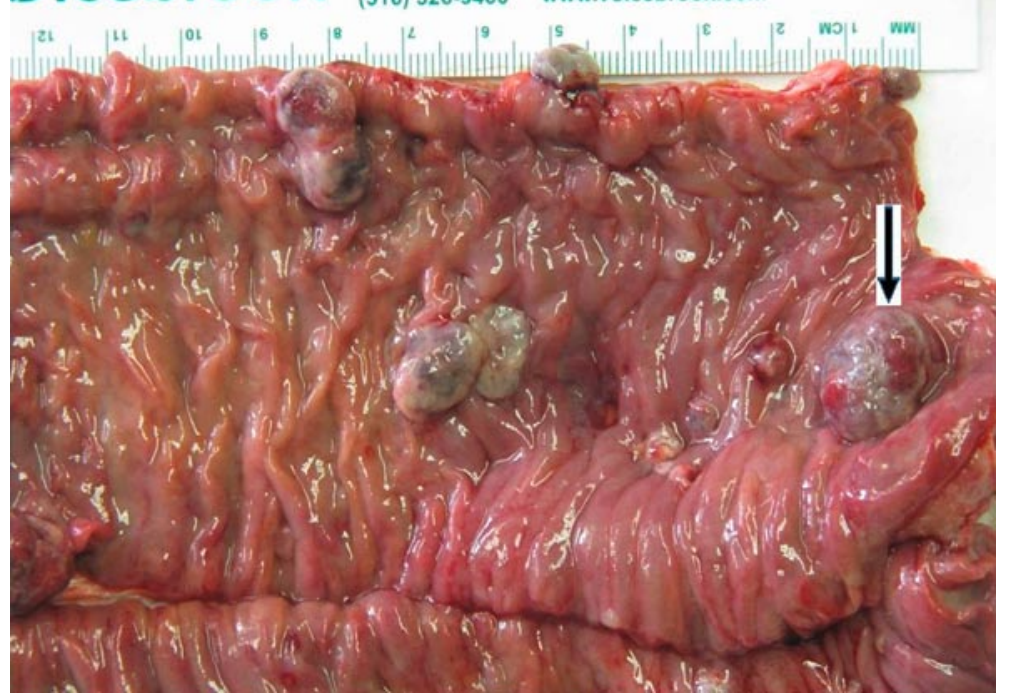

Fig. 4. Gross picture of a segment of small bowel with multiple sessile polyps. One lesion with surface erosion is seen. 


\begin{tabular}{|c|c|c|c|}
\hline $\begin{array}{r}\text { Case Reports in } \\
\text { Gastroenterolooy }\end{array}$ & $\begin{array}{l}\text { Case Rep Gastroenterol 2011;5:471-478 } \\
\text { DOI: } 10.1159 / 000331136\end{array}$ & $\begin{array}{l}\text { Published online: } \\
\text { August 22, } 2011\end{array}$ & $\begin{array}{l}\text { () } 2011 \text { S. Karger AG, Basel } \\
\text { ISSN } 1662-0631 \\
\text { www.karger.com/crg }\end{array}$ \\
\hline
\end{tabular}

\section{References}

1 Garcia JA, Cowey CL, Godley PA: Renal cell carcinoma. Curr Opin Oncol 2009;21:266-271.

-2 Bonsib SM: Renal cystic diseases and renal neoplasms: a mini-review. Clin J Am Soc Nephrol 2009;4: 1998-2007.

3 Chow WH, Dong LM, Devesa SS: Epidemiology and risk factors for kidney cancer. Nat Rev Urol 2010;7: 245-257.

$\checkmark 4$ Mancini V, Battaglia M, Lucarelli G, Di Lorenzo V, Ditonno P, Bettocchi C, Selvaggi FP: Unusual solitary metastasis of the ciliary body in renal cell carcinoma. Int J Urol 2008;15:363-365.

5 Furniss D, Harnden P, Ali N, Royston P, Eisen T, Oliver RT, Hancock BW: Prognostic factors for renal cell carcinoma. Cancer Treat Rev 2008;34:407-426.

6 Bukowski RM: Prognostic factors for survival in metastatic renal cell carcinoma: update 2008. Cancer 2009;115:2273-2281.

7 Bahli ZM, Panesar KJ: Solitary jejunal metastasis from renal cell carcinoma. J Ayub Med Coll Abbottabad 2007;19:62-63.

8 Takeda T, Shibuya T, Osada T, Izumi H, Mitomi H, Nomura O, Suzuki S, Mori H, Matsumoto K, Kon K, Abe W, Beppu K, Sakamoto N, Nagahara A, Otaka M, Ogihara T, Yao T, Watanabe S: Metastatic renal cell carcinoma diagnosed by capsule endoscopy and double balloon endoscopy. Med Sci Monit 2011;17: CS15-CS17.

-9 Yamamoto D, Hamada Y, Okazaki S, Kawakami K, Kanzaki S, Yamamoto C, Yamamoto M: Metastatic gastric tumor from renal cell carcinoma. Gastric Cancer 2009;12:170-173.

-10 Nojima H, Cho A, Yamamoto H, Nagata M, Takiguchi N, Kainuma O, Souda H, Gunji H, Miyazaki A, Ikeda A, Matsumoto I, Asano T, Ryu M, Nihei N, Maruoka M: Renal cell carcinoma with unusual metastasis to the gallbladder. J Hepatobiliary Pancreat Surg 2008;15:209-212.

11 Gammon BL, Gleason BC, Thomas AB, Cibull TL: Sarcomatoid renal cell carcinoma presenting in the oropharynx. J Cutan Pathol 2010;37:1255-1258.

12 Aburto J, Bruckner BA, Blackmon SH, Beyer EA, Reardon MJ: Renal cell carcinoma, metastatic to the left ventricle. Tex Heart Inst J 2009;36:48-49.

13 Srinivasan N, Pakala A, Al Kali A, Rathi S, Ahmad W: Papillary renal cell carcinoma with cutaneous metastases. Am J Med Sci 2010;339:458-461.

14 Chauhan A, Ganguly M, Nath P, Chowdhary GS: Cutaneous metastasis to face and neck as a sole manifestation of an unsuspected renal cell carcinoma. Int J Dermatol 2011;50:81-84.

15 Massaccesi M, Morganti AG, Serafini G, Di Lallo A, Deodato F, Picardi V, Scambia G: Late tonsil metastases from renal cell cancer: a case report. Tumori 2009;95:521-524.

-16 Ielpo B, Mazzetti C, Venditti D, Buonomo O, Petrella G: A case of metachronous splenic metastasis from renal cell carcinoma after 14 years. Int J Surg 2010;8:353-355.

17 Machado NO, Chopra P: Pancreatic metastasis from renal carcinoma managed by Whipple resection. A case report and literature review of metastatic pattern, surgical management and outcome. JOP 2009;10:413-418.

-18 Kramer CK, Ferreira N, Silveiro SP, Gross JL, Dora JM, Azevedo MJ: Pituitary gland metastasis from renal cell carcinoma presented as a non-functioning macroadenoma. Arq Bras Endocrinol Metabol 2010;54:498-501.

19 Kaushik A, Ho L: Thyroid metastasis from primary renal cell cancer on FDG PET/CT. Clin Nucl Med 2011;36: 56-58.

20 Manohar K, Mittal BR, Kashyap R, Bhattacharya A, Singh B: Renal cell carcinoma presenting as isolated thyroid metastasis 13 years after radical nephrectomy, detected on F-18 FDG PET/CT. Clin Nucl Med 2010;35:818-819.

21 Bortnik S, Cohen DJ, Leider-Trejo L, Ron IG: Breast metastasis from a renal cell carcinoma. Isr Med Assoc J 2008;10:736-737.

22 Wu HY, Xu LW, Zhang YY, Yu YL, Li XD, Li GH: Metachronous contralateral testicular and bilateral adrenal metastasis of chromophobe renal cell carcinoma: a case report and review of the literature. J Zhejiang Univ Sci B 2010;11:386-389.

23 Gozen AS, Canda AE, Naser M, Stock C, Rassweiler J, Teber D: Painful leg: a very unusual presentation of renal cell carcinoma. Case report and review of the literature. Urol Int 2009;82:472-476.

24 Rustagi T, Rangasamy P, Versland M: Duodenal bleeding from metastatic renal cell carcinoma. Case Rep Gastroenterol 2011;5:249-257. 
25 Bhatia A, Das A, Kumar Y, Kochhar R: Renal cell carcinoma metastasizing to duodenum: a rare occurrence. Diagn Pathol 2006;1:29.

-26 Loualidi A, Spooren PF, Grubben MJ, Blomjous CE, Goey SH: Duodenal metastasis: an uncommon cause of occult small intestinal bleeding. Neth J Med 2004;62:201-205.

27 Hession PR, Campbell RS: Late presentation of solitary jejunal metastasis from renal cell carcinoma. Int J Clin Pract 1997;51:334-335.

28 Roviello F, Caruso S, Moscovita FS, Marrelli D, Neri A, Rampone B, De Marco G, Perrotta ME, Mariani F: Small bowel metastases from renal cell carcinoma: a rare cause of intestinal intussusception. J Nephrol 2006;19: 234-238.

29 Yamada Y, Hachisuka K, Yamaguchi A, Hori A, Kondo S, Hirose S, Tsubone M: A case of intussusception due to intestinal metastasis of renal carcinoma (in Japanese). Gan No Rinsho 1986;32:1604-1609.

- 30 Deguchi R, Takagi A, Igarashi M, Shirai T, Shiba T, Watanabe S, Kurumada T, Miwa T, Sadahiro S, Yasuda M: A case of ileocolic intussusception from renal cell carcinoma. Endoscopy 2000;32:658-660. 